\title{
Asy-Syakhshiyatu Al-Sardiyatu Wa Tamtsilatuha Fi Thali'ati Kutubi al-Adabi al-Abbasi
}

\section{الشخصيات السردية وتمثلاتها في طليعة كتب الأدب العباسي (نماذج ومختارات)}

\section{El Sayed Mohamed Salem}

Faculty of Languages and Communication

Sultan Zainal Abidin University, Malaysia sayedsalim@uinsza.edu.my

- Received: 06.05.2020 • Accepted: 21. 10.2020 • Published online: 29.11 .2020

Abstract: Literature of its two kinds reached, during the Abbasid era, to the peak of goodness and splendor, whereby the mingling of Arabs with non-Arabs had its far-reaching impacts in refining the ideas and imagination, the maturity of culture, and improving the types of speech; poetry and prose. The narrative discourse took its best chance when the literary arts diversified in that era, and the narration should not be without a time in which events are narrated and characters revolve in its orbit. Hence this study came to shed light on narrative characters because it is the column of narrative narrative construction, and to show the types of narrative characters, and follow these different types of characters in samples from the early books of narration, such as "Fun and Familiarity", "The Animal", "The Statement and Clarification", the "Calella and Damnah" and "Women's News", using the descriptive and the analytical approaches, and thus To explore his gore and to discover its essence.

Keywords: Time paradoxes, Time differences, Abbasid literature, Narration

$$
\begin{aligned}
& \text { الملخص: لقد وصل الأدب بنوعيه في العصر العباسي إلى ذروة حُسنه وروعته؛ حيث كان } \\
& \text { لامتزاج العرب بالأعاجم آثاره البعيدة في تهذيب الأفكار وثقل الأخيلة ونضج الثقافة وتجويد } \\
& \text { ألوان الكلام من شعر ونثر، وقد أخذ الخطاب السردي حظه الأوفر حينما تنوعت الفنون } \\
& \text { الأدبية في ذلك العصر، ولا يتصور أن يكون هناك عمل سردي دون وجود العنصر الحيوي } \\
& \text { الذي يقوم بالأحداث أو تقع عليه الأحداث، ألا وهو الشخصيات؛ فالشخصيات السردية هي }
\end{aligned}
$$


El Sayed Mohamed Salem

أهم مكونات العمل السردي، وهي العنصر الفعال فيه. ومن هنا جاءت هذه الدراسة لإلقاء الضوء على الشخصيات السردية باعتبارها عمود البناء الروائي القصصي، ولبيان أنواع

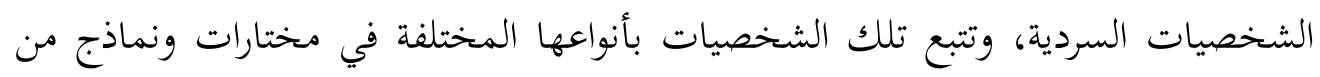

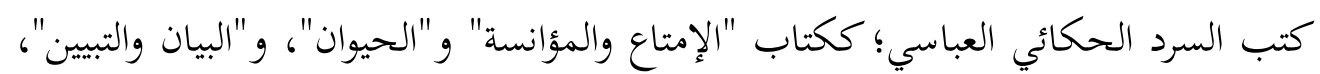

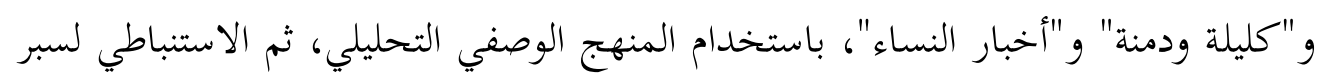
غوره وتبيين جوهره. كلمات دلالية: الشخصيات السردية، الأدب العباسي، السرد

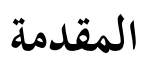

كان الاختلاف قائمًا وسيظل حول ما إذا كان السرد علما له أطر ومفاهيم خاصة به، وله تقنيات تحدد مفهومه؛ أم أن السرد ليس محدد المعالم بقدر ما هو رؤى واتجاهات مختلفة ومتنوعة تسعى جميعها لدراسة السرد نفسه؛ والأسباب كثيرة منها ما يتعلق بطبيعة الدراسات الأدبية، ومنها ما يتعلق بمرجعية الناقد أو الأديب.

ولكي لا نغرق في تلك الإشكالية المتجذرة بعمق تجذّر النقد الأدبي في التاريخ؛ ولإزالة الغموض حول تحديد المصطلح والمفهوم للسرد؛ لا مناص لنا إلا أن نتمثل المقاربة التكاملية بين مدارس النقد الأدبي، بداية من المدرسة الشكلانية الروسية التي تهتم بالأدب نفسه، والحقائق الأدبية، غير آبهة بالبعد النفسي والتاريخي والاجتماعي والجمالي؛ مرورًا بالمدرسة الفرنسية والأنجلو أمريكية المتقاربتين في نظرتيهما للأدب على أساس من النسق التاريخي بشقيه الماضي والمستقبل، وجعلهما من الزمان والمكان ناقلين لأحداث النص السردي، وصولا إلى الرؤية العربية للسرد؛ وبناء على المقاربة التكاملية التي ترى بالجمع بين تلك الرؤى، آخذة بعين الاعتبار السياق الاجتماعي ورؤية الراوي، وتتابع الأحداث في أزمنتها وأمكنتها؛ وعلى أساس من هذا يمكن أن نخرج بتعريف للسرد بأنه: طريقة تستخدم تقنيات وأدوات 
El Sayed Mohamed Salem

لتحليل النص السردي ومحتواه، وتفكيك عناصره من أحداث وشخصيات وزمان ومكان، وصولا إلى المضامين والدلالات، بعناصرها الفنية واللغوية، تأخذ المتلقي إلى مرحلة المشاركة القائمة على الفهم والاستمتاع والقبول، وهو بعبارة أبسط: عرض لتتابع الأحداث، يتداخل فيه كل من السياق الاجتماعي ورؤية الراوي، أو هو رواية لحديث متتابع الأجزاء في تماسك وترابط وتناسق، والشرط الأساسي لجودة العمل السردي الرواية الحسنة، بحيث يجذب ذهن القارئ أو السامع وعقلهما، فنجد المتلقي للسرد في انتباه عميق . ويقوم أي عمل سردي على عناصر أربعة:

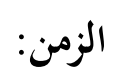

الزمن في المفهوم الأدبي هو زمن إنساني، أي أنه ليس زمنًا بالمفهوم التقليدي كتحديد للوقت، بل هو زمن نسبي يختلف من كاتب لآخر تبعًا للفرد نفسه وحالته وخبرته الذاتية؛ فهو زمن غني بالحياة الداخلية والأحداث. ووجود الزمن في السرد هو وجود لازم، فلا سرد بدون زمن يُحكى في إطاره الأحداث وتدور الشخصيات في فلكه، فالزمن هو الذي يجمع كل العناصر السردية.

\section{المكان:}

المكان في أي عمل سردي أو قصصي أو حكائي يُعد من العناصر الأساسية التي ترتكز عليها عملية السرد. والمكان إما أن يكون مطلقا أي ثابتا، أو فنيا أي نسبيا، وعلى الرغم أن الروائي أو الكاتب ينطلق في روايته من مكان مطلق إلا أنه ينسج لنا مكانًا فنيًّا يتمرد على لى

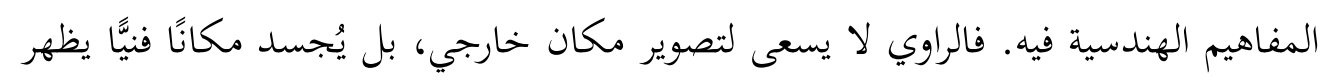
في لوحة مصنوعة من الكلمات؛ الهدف منها إثارة المتلقي ليتحول المشهد إلى تصور ذهني؛ له مقوماته الخاصة وأبعاده المتميزة.

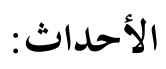


El Sayed Mohamed Salem

الأحداث هي سرد "لأخبار الماضين وأفعالهم، وما طرأ على حياتهم وأوضاعهم حسبما

يتناقله الرواة ويتحدث به اللاحقون عن السابقين ممن شاهدوا ذلك الخبر أو سمعوه (صحراوي، 2008 ص 52) ولا تكتسب الأحداث قيمتها الفنية إلا ضمن النسيج القصصي الكّلي، حيث تتفاعل مع مختلف المكونات السردية لهذا البناء الفني، ويقترن انتقال الأحداث وتطورها الانتقال بعناصر الحكاية الرئيسة وهي الزمان والمكان.

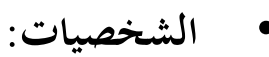

الشخصية السردية هي أهم مكونات العمل الحكائي؛ حيث إنها العنصر الفعّال الذي يقوم بالأعمال التي تتحد وتتماسك معا لتكوّن السرد، كما أنها المحرّك للأحداث والدافع بها إلى التطور، بل هي أساس البناء الروائي القصصي، ولا يمكن قيام العمل الحكائي بدونها، سواء أكانت هذه الشخصية شخصية حقيقية من لحم ودم كما يرى الواقعيون، أم كانت كائنًا من ورق يصنعها الخيال الفني.

والنظر إلى العمل السردي يجب أن يكون شاملا لعناصره كافة، كما أن النظر لأي من أطراف العمل بنظرة أحادية لا يظهر العمل للعيان؛ فالعمل لا يظهر إلا متضافًاً بعوامله المتشاركة في ظهوره، وإلا ظهر النقص والخلل، فلا يجوز تغليب طرف على آخر، فكل العناصر مهمة لأنها أسهمت في تكوين العمل، وتشكيل مقوماته الأساسية؛ إلا أننا سنقف في هذا البحث على الشخصيات السردية وأنواعها؛ باعتبارها عمود البناء الروائي والقصصي. منهجية البحث

تختلف مناهج البحث من بحث لآخر، ولقد استدعى تطبيق الدراسة اتباع:

- المنهج الوصفي: وهو المنهج الذي يقوم على جمع البيانات والمعلومات والتفاصيل حول المشكلة أو الهدف المراد إجراء البحث العلمي عليه، ويجيب على عدة تساؤلات 
El Sayed Mohamed Salem

مثل: كيف وأين ومتى ولماذا، كما استدعت الدراسة تطبيق المنهج الاستباطي، وهو منهج يربط بين المقدمة والموضوع وعلله والنتائج؛ على أساس التأمل والمنطق، كما أنه دائمًا يبدأ بالكل ويتدرَّج إلى الجزء.

- المنهج التحليلي: حيث نقوم بتفكيك وإرجاع العناصر إلى أصولها، ودراسة طبيعتها ووظائفها؛ ويتلخص هذا المنهج في عمليات ثلاث قد تجتمع كلها أو بعضها في العمل الواحد، وهي: التفسير: أي التفكيك، والنقد: أي التقويم، ثم الاستنباط، أي التركيب. وعليه تم الاعتماد عاى هذه المناهج الثلاثة لتجلية الشخصيات السردية وتوصيفها في طليعة كتب العصر العباسي، ومن ثم تحليلها والوقوف على ملامحها ومميزاتها وخصائصها؛ تبيانا لها وتوضيحا لمعالمها، وسردا لأنواعها.

نتائج الدراسة وتحليلها الشخصية في اللغة

شخص: رأيت أشخاصًا وشخوصًا، وامرأة شخيصة، كقولك: جسيمة، وشَخَصَ من مكانه، وأشخصته (الزمخشري، د. ت. ص 498). والشخصية عند ابن منظور هي سواد الإنسان وغيره، تراه من بعيد، وكل شيء رأيت جسمانه فقد رأيت شخصه، والشخص هو كل جسم له ارتفاع وظهور، وجمعه أشخاص وشخوص وشِخاص، وشَخَصَ تعني ارتفع، والشخوص ضد الهبوط، كما يعني السير من بلد إلى بلد، وشَخَصَ ببصره أي رفعه فلم يطرف

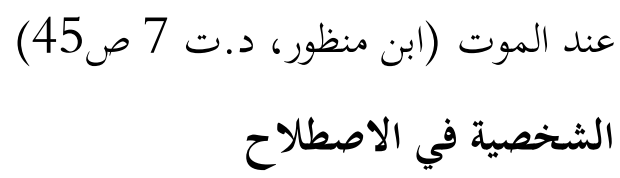

التعريف بالشخصية يشوبه التعقيد "كونها ذات طبيعة مطاطية، جعلتها خاضعة لكثير من المقولات والتفسيرات دون أن تستقر الدراسات على تعريف لها (بحراوي، 2009 ص 
El Sayed Mohamed Salem

207)، و "من الصعب تحديد تعبير الشخصية الأدبي (ناصر الحجلان، 2009 ص 49 - 50)؛ فيختلف تعريف الشخصية في الاصطلاح باختلاف الاتجاه الروائي الذي يتناول الحديث عنها؛ فهي لدى الواقعيين الشخصية التي تحاكي الواقع الإنساني المحيط، أما بالنسبة للرواية الحديثة فما هي بالنسبة لهم سوى مزيج من الخيال الفني والثقافي، والذي يسمح للروائي أن يضيف ويحذف ويبالغ ويضخم في تكوينها وتصويرها؛ فهي شخصية من اختراع الروائي

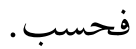

\section{مفهوم الشخصية}

الشخصية هي أحد مكونات العمل الحكائي وأهمها؛ فهي العنصر الحيوي الذي ينهض بالأفعال التي تترابط وتتكامل في الحكي (يقطين، 1997 ص 87)، وظلت الشخصية محط عناية الدارسين قديمًا وحديثًا؛ عدا أرسطو الذي أعد الشخصية مفهومًا ثانويَّا خاضعًا كليَّا لمفهوم العمل (مرشد، 2005 ص 34)؛ حيث كانت تمثل عنده ظلا للأحداث (الحجلان، 2009 ص 56) فالتراجيديا عنده ليست محاكاة للأشخاص بل للأعمال والحياة (أرسطو، 1973 ص 50)، واستعادت الشخصية أهميتها على يد الكلاسيكيين الجدد في عصر النهضة، وصار فيما بعد ينظر إلى العمل الدرامي والروائي في مدى قدرته على خلق الشخصيات.

ويرى بحراوي أن الشخصية ما هي "إلا نتاج يُبدعه المُبدع بناءً على اختيارات جمالية خاصة، فالشخصيات لا وجود لها خارج الكلمات لأنها ليست سوى كائنات من ورق (بحراوي، 1990 ص 213).

أما الشخصية في نظر مرتاض فهي "هذا العالم المعقد الشديد التركيب المتباين التنوع بتعدد الأهواء والمذاهب والأيديولوجيات والثقافات والحضارات والهواجس والطبائع البشرية التي ليس لتنوعها ولا لاختلافها من حدود (مرتاض، د. ت.ص 107). 
El Sayed Mohamed Salem

وسواء أكانت الشخصية شخصية حقيقية (شخص) من لحم ودم كما يرى الواقعيون، أم كانت كائنًا من ورق يصنعها الخيال الفني مع النسق الثقافي؛ إلا أنها هي المحرك للأحداث والدافع بها إلى التطور؛ بل هي عمود البناء الروائي القصصي، ولا يمكن قيام العمل الحكائي بدونها. وهو ما اتفق معه تمام الاتفاق بويجرة بقوله: "الشخصية العمود الفقري للعمل الروائي (بويجرة، 1983 ص 5) والتي تقوم بفعل معين على خط زمني وفي إطار مكاني معين؛ "هدفها الجوهري ربط أحداث القصة لإتمام المعنى (طالب، 2005 ص 34). أنواع الشخصيات

بعد العرض لمفهوم الشخصية نتحدث عن أنواع الشخصيات وتصنيفاتها؛ فهناك تصنيفات شكلية للشخصية الروائية ووظيفتها داخل السرد، وبناء على الثبات والتغيير تنقسم الشخصية إلى ساكنة ثابتة لا تتغير، وأخرى دينامية نامية (ناصر، 2010 ص 180). وهناك تصنيف ثان بحسب أهمية الشخصية في الرواية أو الوظيفة التي تؤديها، فتكون إما شخصية رئيسة محورية أو شخصية ثانوية مرحلية (قاسم، 1984 ص 130-131)؛ أما "فيليب هامون" وانسجامًا مع تصوره الذي ينهل من اللسانيات؛ فقد قسم الشخصية إلى ثلاثة أنواع: الشخصية المرجعية، والشخصية الإشارية الواصلة، والشخصية الاستذكارية المتكررة (بنكراد، 1994 ص

\section{الشخصيات المرجعية}

"هي شخصيات تاريخية وشخصيات أسطورية، وشخصيات مجازية (الحب والكراهية)، وشخصيات اجتماعية، تحيل هذه الشخصيات كلها على معنى ممتلى وثابت حددته ثقافة ما (هامون، 1990 ص 24) وتلك الشخصيات التي تعود إلى واقع تاريخي ورد في النص الحكائي يستعين بها الراوي في إبراز وظيفة دلالية ما. أولا: الشخصيات المرجعية في "أخبار النساء" 
El Sayed Mohamed Salem

إذا بحثنا في كتاب "أخبار النساء" فإننا نجد استخدام الشخصيات المرجعية استخدامًا مفرطًا، حتى إنه لا يوجد جزء من خبر إلا وله شخصية مرجعية، يقص الخبر عنها أو على لئ لسانها. ومن الشخصيات المرجعية التي تناولها الكتاب؛ شخصية سيدنا "عمر" رضي الله عنه، والتي نستطيع أن نقول عنها إنها شخصية مرجعية ومتكررة.

فجاءت شخصية سيدنا عمر بوصفها شخصية مرجعية في باب "ما جاء في وصف النساء": "شكت امرأةٌ إلى زوجها قلّة إتيانه إليها، فقال لها: أنا وأنت على قضاء عمر، قالت: قضى عمر أنّ الرّجل إذا أتى امرأته في كلّ طهرٍ فقد أدّى حقّها (ابن الجوزي، 1982 ص 9). كما جاءت شخصية "معاوية بن أبي سفيان" من الشخصيات المرجعية والمتكررة في العديد من المواقف؛ منها ما جاء في باب "الزنا والتحذير من عواقبه": "ثمّ أخرجه معاوية إلى بـ بـ المسجد، وجمع النّاس، فقام أبو مريم السّلولي فقال: أشهد أنّ أبا سفيان قدم علينا بالطّائف، وأنا خمّارٌ بالجاهليّة (ابن الجوزي، 1982 ص 212). ومن الشخصيات الأدبية المرجعية شخصية الأصمعي؛ وهو أحد راوية العرب، وأحد أئمة العلم باللغة والشعر، وتم الاستشهاد بمقولاته في أكثر من موقع في الكتاب، منها ما جاء في باب "وصف النساء": "قال الأصمعي: بنات العمّ أصبر، والغرائب أنجب. وما ضرب رؤوس الأبطال كابن عجميّة (ابن الجوزي، 1982 ص 12). وأيضًا ما جاء في باب "وفاء النساء": "حكى الأصمعي، عن رجلٍ من بني ضبّة قال: ضلّت لي إبلٌ فخرجت في طلبها حتّى أتيت بلاد بني سليم، فلمّا كنت في بعض تخومها، إذا جاريةٌ غشى بصري إشراق وجهها، فقالت: ما بغيتك فإنيّ أراك مهمومًا؟ قلت: إبلٌ ضلّت لي، فأنا في طلبها. قالت: فتحب أن أرشدك إلى من هي عنده؟ قلت: نعم. قالت: الذي أعطاكهنّ هو الذي أخذهنّ فإن شاء ردّهنّ (ابن الجوزي، 1982 ص 125). ثانيا: الشخصيات المرجعية في "الإمتاع والمؤانسة" 
El Sayed Mohamed Salem

جاءت شخصية معاوية بن أبي سفيان من الشخصيات المرجعية التاريخية والمتكررة الاستخدام أيضًا بكثرة في "الإمتاع والمؤانسة"، ومنها ما جاء: "إنّ رهطًا من الأنصار دخلوا على معاوية، فقال: يا معشر الأنصار، قريش خير لكم منكم لهم، فإن يكن ذلك لقتلى أحد، فقد قتلتم يوم بدر مثلهم، وإن يكن لإمرة فوالله ما جعلتم لي إلى صلتكم سبيلا، خذلتم عثمان يوم الدار، وقتلتم أنصاره يوم الجمل، وصليتم بالأمر يوم صفّين. (التوحيدي، 2003 ص 383). وجاءت شخصية الأصمعي من الشخصيات الأدبية الشعرية المرجعية في "الإمتاع والمؤانسة"، ومنها ما جاء في الليلة الثالثة والثلاثين: "حدّثنا الأصمعيّ قال: قال "أبو طفيلة الحرمازيّ": قال أعرابيّ: ضفت رجلا فأتانا بخبز من برّ كأنّه مناقير النّران(1)، وأتانا بتمر كأعناق الورلان. (التوحيدي، 2003 ص 333).

ومن الشخصيات الدينية المرجعية شخصية عمر بن الخطاب رضي الله عنه، والتي تم ذكرها في أكثر من ليلة من ليالي "الإمتاع والمؤانسة"، ومنها ما ذُكر في الليلة السابعة: "وقال عمر بن الخطّاب رضي الله عنه: لو كان المرء أقوم من قدح لوجد له غامز. وآل ابن وهب وابن ثوابة كانوا أنبل وأفضل وأعقل من أن يظنّ بهمّ ما لا يظنّ بخساس (التوحيدي، 2003

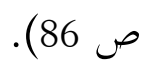

ومن الشخصيات التاريخية المرجعية شخصية عبد الملك بن مروان، وقد ذُكر في أكثر من ليلة، منها ما جاء في (الليلة الخامسة والعشرين): "وقال ابن دأب: قال لي ابن موسى: اجتمعنا عند عبد الملك بن مروان فقال: أيّ الآداب أغلب على الناس؟ فقلنا، فأكثرنا في كل نوع، فقال عبد الملك: ما الناس إلى شيء أحوج منهم إلى إقامة ألسنتهم التي بها يتعاورون القول، ويتعاطون البيان، ويتهادون الحكم، ويستخرجون غوامض العلم من مخابئها، ويجمعون

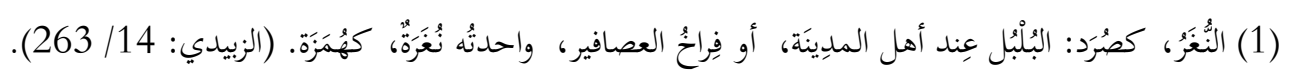
Indonesian Journal of Arabic Studies, Volume (2), Issue (2), November 2020 
El Sayed Mohamed Salem

ما تفرَّق منها، إن الكلام فارق للحكم بين الخصوم، وضياء يجلو ظلم الأغاليط، وحاجة الناس إليه كحاجتهم إلى مواد الأغذية. (التوحيدي، 2003 ص 256).

ومن الشخصيات الدينية المرجعية شخصية عمر بن عبد العزيز، وقد ذُكر في أكثر من

ليلة، منها ما جاء في "الليلة الأولى": "قال عمر بن عبد العزيز: والله إني لأشتري ليلة من

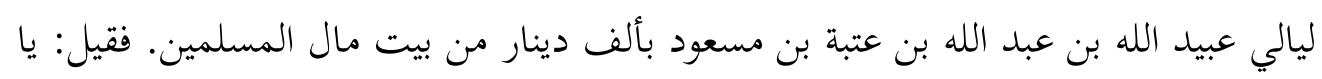
أمير المؤمنين، أتقول هذا مع تحرِّك وشدة تحفظك وتنزهك؟ فقال: أين يذهب بكم؟ والله إني لأعود برأيه ونصحه وهدايته على بيت مال المسلمين بألوف وألوف دنانير، إنَّ في المحادثة تلقيحًا للعقول، وترويحًا للقلب، وتسريحًا للهمّ، وتنقيحًا للأدب (التوحيدي، 2003 ص 46-

\section{ثالثا: الشخصيات المرجعية في "البيان والتبيين"}

من الشخصيات الدينية المرجعية في البيان والتبيين شخصية "موسى بن عمران"، وجاءت

في باب "العي": "وسأل الله عز وجل موسى بن عمران عليه السلام، حين بعثه إلى فرعون بإبلاغ رسالته، والإبانة عن حجته، والإفصاح عن أدلثه، فقال حين ذكر العقدة (الجاحظ، 1423هـ ص 30) كما جاءت أيضًا في باب "منافع العصا ومرافقها": "إن موسى بن عمران صلّى الله عليه وسلّم حين آنس من جانب الطور نارًا، وأراد الاقتباس لأهله منها، لم يأتِ النار في مقدار تلك المسافة القليلة إلا ومعه عصاه، فلما صار بالوادي المقدس من البقعة المباركة قيل له: ألقِ عصاك، واخلع نعليك. فرمى بنعليه راغبًا عنهما، حين نزّه الله ذلك الموضع عن الجلد غير الذكي، وجعل الله جماع أمره من أعاجيبه وبرهاناته في عصاه، ثم كلمه من جوف شجرة ولم يكلمه من جوف إنسان ولا جان (الجاحظ، 1423هـ ص 21/2).

كما كانت شخصية عمر بن الخطاب رضى الله عنه من الشخصيات الدينية المستخدمة بكثرة كمرجعية لكثير من المواقف، ومنها: "وقال عمر بن الخطاب رحمه الله في سهيل بن 
El Sayed Mohamed Salem

عمرو الخطيب: يا رسول الله، انزع ثنيتيه السفليين حتى يدلع لسانه، فلا يقوم عليك خطيبًا أبدًا (الجاحظ، 1423هـ ص 14-15)

ومن الشخصيات التاريخية المرجعية شخصية معاوية بن أبي سفيان في باب "الخطباء

الشعراء": "ودخل الأحنف بن قيس على معاوية بن أبي سفيان، فأشار له إلى الوساد فقال له: اجلس. فجلس على الأرض، فقال له معاوية: وما منعك يا أحنف من الجلوس على الوساد؟ فقال يا أمير المؤمنين، إن فيما أوصى به قيس بن عاصم المنقري ولده أن قال: الا تغشَ السلطان حتى يملك، ولا تقطعه حتى ينساك، ولا تجلس له على فراش ولا وساد، واجعل بينك وبينه مجلس رجل أو رجلين، فإنه عسى أن يأتي من هو أولى بذلك المجلس منك فتقام له، فيكون قيامك زيادة له، ونقصانًا عليكه. حسبي بهذا المجلس يا أمير المؤمنين، لعله إن يأتي من هو أولى بذلك المجلس مني، فقال معاوية: القد أوتيت تميم الحكمة، مع رقة حواشي الكلم (الجاحظ، 1423هـ ص 66).

وأيضًا جاء الاقتباس من مأثورات الشخصية في باب "من الكلام المحذوف": "من

معاوية بن أبي سفيان إلى زياد بن أبي سفيان. أما بعد؛ فإن لك رأيين: رأيًا من أبي سفيان ورأيًا من سمية. فأما رأيك من أبي سفيان فحلم وحزم، وأما رأيك من سمية فكما يكون رأي مثلها. وقد كتب إليّ الحسن بن علي إنك عرضت لصاحبه، فلا تعرضن له، فإني لم أجعل لك إليه سبيلا، وإن الحسن بن عليم من لا يرمى له الرجوان، والعجب من كتابك إليه لا تنسبه إلى أبيه (الجاحظ، 1423هـ ص 205/2).

ومن الشخصيات التاريخية المرجعية شخصية الحجاج بن يوسف الثقفي، فقد تكرر ذكرها في الكتاب، وتحت عنوان: (خطبة الحجاج بعد دير الجماجم) قال الجاحظ: "فقال: يا أهل العراق، إن الشيطان قد استبطنكم فخالط اللحم والدم، والعصب والمسامع، والأطراف والأعضاء، والثِّغاف، ثم أفضى إلى الأمخاخ والأصماخ، ثم ارتفع فعشَّش، ثم باض وفَّخ، 
El Sayed Mohamed Salem

فحشاكم نفاقًا وشقاقًا، وأشعركم خلافًا، واتخذتموه دليلا تتبعونه، وقائدًا تطيعونه، ومؤامرًا تستشيرونه، فكيف تنفعكم تجربة، أو تعظكم وقعة، أو يحجزكم إسلام، أو ينفعكم بيان. ألستم أصحابي بالأهواز؛ حيث رمتم المكر، وسعيتم بالغدر، واستجمعتم للكفر، وظنتم أن الله يخذل دينه وخلافته، وأنا أرميكم بطرفي؛ وأنتم تسللون لواذًا، وتنهزمون سراعًا (الجاحظ، 1423 صه ص 95/2)

\section{رابعا: الشخصيات المرجعية في كتاب "الحيوان"}

من الشخصيات المرجعية الدينية التي وردت في كتاب الحيوان شخصية سيدنا "موسى" في باب "القول في الشياطين": "القول في موسى بن عمران ومن كان معه في التّيه، فقد كانوا أمّة من الأمم يتكسّعون أربعين عامًا (الجاحظ، 1423هـ ص 204/4). وتكرر أيضًا استخدام الشخصية في باب "الورع الذي يبغضه الله تعالى": "ولقد دخل علينا فتى حدث كان قد وقع إلى أصحاب عبد الواحد بن زيد ونحن عند موسى بن عمران، فدار الحديث إلى أن قال الفتى: أفطرت البارحة على رغيف وزيتونة ونصف، أو زيتونة وثلث، أو زيتونة وثلثي زيتونة، أو ما أشبه ذلك. بل أقول: أكلت زيتونة، وما علم الله من أخرى، فقال موسى: إنّ من الورع ما يبغضه الله، علم الله؛ وأظنّ ورعك هذا من ذلك الورع (الجاحظ، 1423هـ ص 19/3). ومن الشخصيات التاريخية الإسلامية المستخدمة في الكتاب شخصية معاوية بن أبي سفيان، ومما جاء في باب "صعوبة كتب الأخفش": "قال معاوية بن أبي سفيان، رضي الله عنهما، لصحار العبدي: ما الإيجاز؟ قال: أن تجيب فلا تبطئ، وتقول فلا تخطئ. قال معاوية: أو كذلك تقول (الجاحظ، 1423هـ ص 62/1).

وجاءت شخصية الأصمعي من الشخصيات المرجعية الأدبية المستخدمة وبكثرة

شديدة في الكتاب، ومنها ما جاء في "تعريف الدهاة" بقوله: "قال الأصمعي: الدهاة أربعة: 
El Sayed Mohamed Salem

معاوية للروية، وعمرو بن العاص للبديهة، والمغيرة بن شعبة للمعضلة، وزياد لكل كبيرة وصغيرة (الجاحظ، 1423هـ ص 457/7)

ومن الشخصيات الدينية شخصية عمر بن الخطاب رضي الله عنه، والتي ذُكرت في

أكثر من موضع، منها ما جاء في باب "منهجا امرأته": "وقال عمر بن الخطّاب: اكفي بالمرء عيبًا أن تكون فيه خلة من ثلاث: أن يبدو لهمن أخيهما يخفي عليه من نفسه، أو يعيب شييًا ثم يأتي مثله، أو يؤذي جليسه فيما لا يعنيه (الجاحظ، 1423هـ ص 96/7). ومن الشخصيات الشعرية المرجعية شخصية الفرزدق، فقد استشهد بشعره في كثير من المواضع، منها ما جاء تحت عنوان: "من هجته زوجته": وقال الفرزدق (الجاحظ، 1423هـ

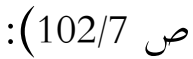

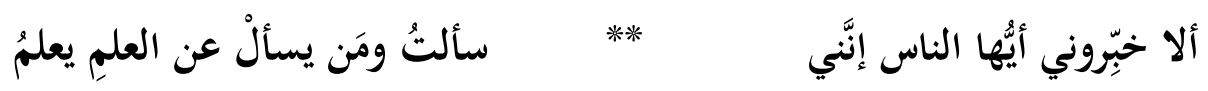

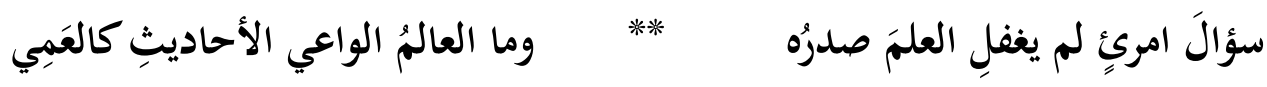
المطلب الثاني: الشخصيات الرئيسة والثانوية الشخصيات الأساسية هي التي يعتمد أحداث الكتاب على وجودها، فتظهر في الأحداث بشكل متكرر، وهي في الغالب شخصيات متعددة الأبعاد، أما الشخصيات الثانوية فهي شخصيات غير مركزية، تتواجد كمكمل للشخصيات الأساسية وكمساعد بتطور الأحداث. ومن الملاحظ في كتب الأدب في العصر العباسي تعدد الشخصيات الرئيسة وكذلك تعدد الشخصيات الثانوية، ولعل ذلك يرجع إلى تناول الكتب لأكثر من موضوع، كما في كتاب "الإمتاع والمؤانسة"، والمنقسم إلى أربعين ليلة؛ كل ليلة بموضوعات مختلفة عن سابقتها ولاحقتها. أولا: الشخصيات الئيسة والثانوية في كتاب "البيان والتبيين" 
El Sayed Mohamed Salem

\section{أ. الثخصيات الئيسة}

يتميز كتاب البيان والتبيين بوجود العديد من الشخصيات الرئيسة والمتكررة في العديد من المواقف والأحداث، منها للمثال لا للحصر شخصية سيدنا موسى عليه السلام، والتي تكررت

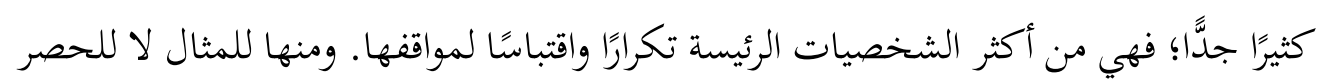
ما جاء في باب "بلاغة النبي" وطلب سيدنا موسي بأن يشد الله من أزره بأخيه هارون. وشخصية عمر بن الخطاب رضي الله عنه، وقد تكرر ذكر الشخصية وأحداث ومقولات خاصة بها أكثر من ثلاث وسبعين مرة.

ومن المقولات الشهيرة لسيدنا عمر بن الخطاب في باب "الأحاديث ووسائل ونصائح

متفرقة": "فلقد وصانا سيدنا عمر بعدم مصاحبة ومؤاخاة الأحمق، فالضرر منه أكثر من نفعه". كما جاء في باب "اققوال وأشعار في الطلب والدعاء": "ما وجد أحد في نفسه كبرًا

إلا من مهانة يجدها في نفسه". وهيمن أجمل أقوال سيدنا عمر بن الخطاب الفاروق رضي

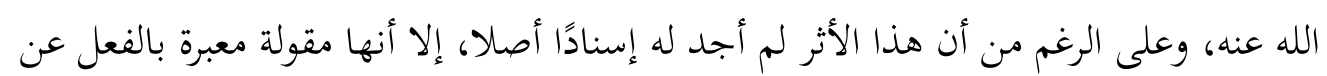
كل صاحب كبر في نفسه.

كما جاءت شخصية معاوية بن أبي سفيان من الشخصيات الرئيسة أيضًا، والتي تكررت تسع مرات في مواقف مختلفة، منها ما جاء في باب "الخطباء والشعراء" وموقف الأحنف بن قيس(2) معه؛ والذي يدل على حكمته في الحديث مع معاوية، فقد كان الأحنف مثالا في الحلم والورع والكلام بحكمة.

(2) التابعي الأحنف بن قيس بن معاوية بن حصين، الأمير الكبير العالم النبيل، أبو بحر التميمي اسمه ضحاك،

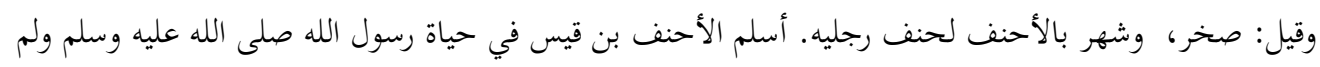

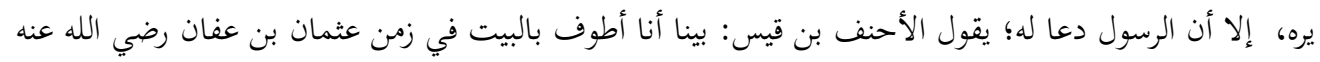

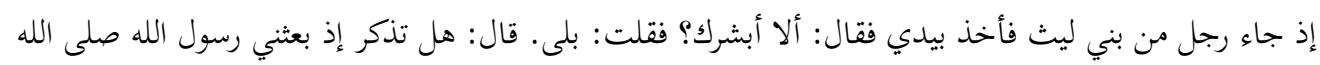

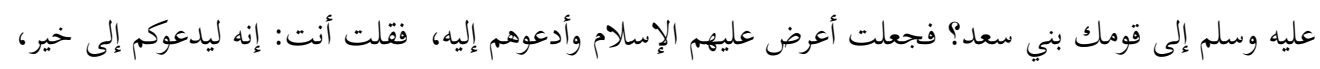


El Sayed Mohamed Salem

كما جاء في باب "مفهوم البلاغة عند العرب" الاستدلال بكلام معاوية بن أبي سفيان مع صحار بن عياش العبدي وقومه، لسر بلاغتهم وفصاحتهم، وأنها حق إحاطةٌ القول بالمعنى، واختيار الكلام، وحسن النظم حتى تكون الكلمة مقاربة أختها، ومعاضدة شكلها، وأن يقرب بها البعيد، ويحذف منها الفضول.

ومن الشخصيات التاريخية الرئيسة في "البيان والتبيين" شخصية عمر بن عبد العزيز

الخليفة الزاهد، وقد تكررت المواضع التي ذُكر فيها، أو استشهد بكلامه، منها ما جاء تحت عنوان: "من اللغز في الجواب": "وقال عمر بن عبد العزيز: إذاكان في القاضي خمس خصال فقد كمل: علم ما كان قبله، ونزاهة عن الطمع، وحلم عن الخصم، واقتداء بالأئمة، ومشاورة

$$
\text { أهل الرأي (الجاحظ، 1423هـ ص 102/2). }
$$

ومن الشخصيات الشعرية الرئيسة في "البيان والتبيين" شخصية النمر بن تولب؛ وهو

شاعر مخضرم تكررت أشعاره في العديد من المواقف والأحداث، منها ما جاء في باب "الخطباء والشعراء"، حيث قال النمر في أشداق الجمل:

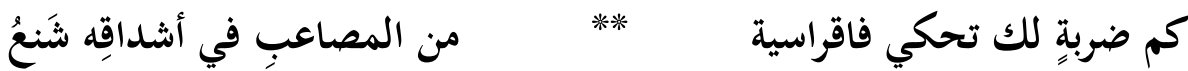

ومن الشخصيات الرئيسة الشعرية شخصية "أبو العيال الهذلي"، والتي تم الاستعانة

بأشعارها في العديد من الأحداث زادت عن اثنتي وعشرين مرة لتوضيحها، منها للمثال لا للحصر ما جاء في باب "مدح اللسن والبيان والكلام الجميل":

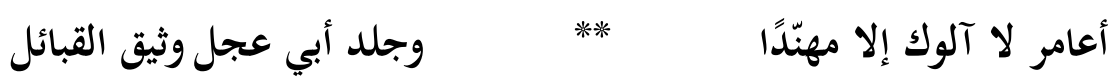

وما حسن إلا حسنًا، فبلغت ذلك إلى رسول الله صلى الله عليه وسلم، فقال رسول الله صلى الله عليه وسلم:

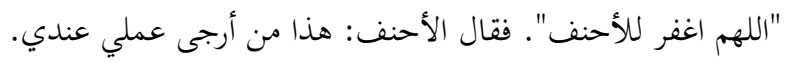


El Sayed Mohamed Salem

ومن الشخصيات الأدبية شخصية ابن المقفع، وقد تكرر ذكره في "البيان والتبيين" تسع مرات. وفي باب (تراجم البلغاء): "قال إسحاق بن حسان بن قوهيّ: لم يفسر البلاغة تفسير ابن المقفع أحد قط. سئل ما البلاغة؟ قال: البلاغة اسم جامع لمعالٍ تجري في وجوه كثيرة. فمنها ما يكون في السكوت، ومنها ما يكون في الاستماع، ومنها ما يكون في الإشارة، ومنها ما يكون في الاحتجاج، ومنها ما يكون جوابًا، ومنها ما يكون ابتداءً، ومنها ما يكون شعرًا، ومنها ما يكون سجعًا وخطبًا، ومنها ما يكون رسائل. فعامة ما يكون من هذه الأبواب الوحي فيها، والإشارة إلى المعنى، والإيجاز، هو البلاغة (الجاحظ، 1423هـ ص 114/1). ب. الشخصيات الثانوية:

من الشخصيات الثانوية، شخصية ابن أحمر الباهل، ومحرز بن علقمة، ومكي بن سواده، وكلهم من الشعراء. وكذلك شخصية يحيى بن خالد البرمكي، وهو من أشهر الشخصيات في

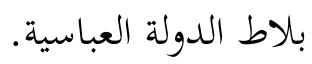

ثانيا: الشخصيات الئيسة والثانوية في كتاب "الإمتاع والمؤانسة" أ. الشخصيات الئيسة

من الشخصيات الرئيسة التي جاءت في "الإمتاع والمؤانسة" شخصية أبو سليمان المنطقي، والتي تكرر ذكرها في الكتاب العديد من المرات، منها في نبذة عن كتاب "الإمتاع والمؤانسة" ووصف للمناقشات التي تجري ما بين الوزير وأبي حيان التوحيدي حول الكتاب ولياليه. كما جاءت شخصية سيدنا عمر بن الخطاب رضى الله عنه من الشخصيات الرئيسة، والتي تكررت إحدى عشرة مرة، تمحورت كلها ما بين الخطب والنصح، مثلما جاء في "الليلة السابعة": "قال عمر بن الخطّاب -رضي الله عنه-: لو كان المرء أقوم من قدح لوجد له غامز

$$
\text { (التوحيدي، } 2003 \text { ص 86). }
$$


El Sayed Mohamed Salem

وتعد شخصية ابن المقفع من الشخصيات الأدبية الرئيسة؛ فقد تكرر ذكره كثيرًا في "الإمتاع والمؤانسة". جاء في الليلة (السابعة عشر): "قال ابن المقفع: عمل الرجل بما يعلم أنه خطأ هوى، والهوى آفة العفاف، وتركه العمل بما يعلم أنه صواب تهاون، والتهاون آفة الدين، وإقدامه على ما لا يعلم أصواب هو أم خطأ لجاج، واللجاج آفة الرأي". (التوحيدي، (174 2003

\section{الثخصيات الثانوية}

ومن الشخصيات الثانوية التي جاءت في "الإمتاع والمؤانسة" شخصية معاوية بن أبي سفيان، وشخصية ابن يعيش، والتي تكررت في "الليلة الثامنة" و "الليلة الخامسة عشرة" فقط كشخصية واصلة لتوصيل فكرة أو مفهوم، كما حدث في "الليلة الثامنة" من إيصال فكرة أن عمر الإنسان قصير والعلم كثير فالواجب أن يحاول الإنسان التحصيل والعلم ما دامت به حياة. ومن الشخصيات الثانوية أيضًا والمعروفة شخصية "ابن الفرات"، وهو الوزير الكبير

أبو الحسن؛ علي بن أبي جعفر محمد بن موسى بن الحسن بن الفرات العاقولي الكاتب. كان ابن الفرات يتولى أمر الدواوين زمن المكتفي، فلما ولي المقتدر ووزر له العباس بك بـ بن الحسن، بقي ابن الفرات على ولايته، فجرت فتنة ابن المعتز، وقتل العباس الوزير، فوزر ابن

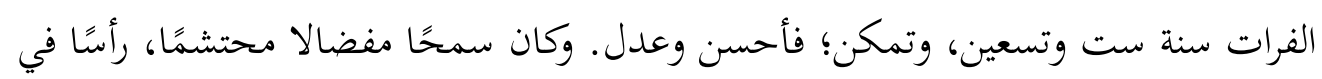
حساب الديوان. له ثلاثة بنون: المحسن والفضل والحسين. ثم عزل في ذي الحجة سنة تسع وتسعين، ثم وزر في سنة أربع ومائة إثر عزل علي بن عيسى، ثم عزل بعد سبعة عشر شهرًا بحامد بن العباس، ثم وليها سنة إحدى عشر وثلاثمائة، وولى ولده المحسن الدواوين، فعسف وصادر وعذب، وظلم أباه أيضًا، واستأصل جماعة، فعزل بعد سنة إلا أيامًا، وقيل: إنه وصل المحدثين بعشرين ألف درهم (الذهبي، 2001 ص 475). ثالثا: الشخصيات الرئيسة والثانوية في كتاب "الحيوان" 
El Sayed Mohamed Salem

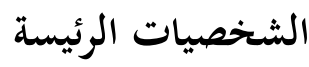

من الشخصيات الرئيسة الدينية التي تم الاستعانة بها شخصية سيدنا موسى بن عمران عليه السلام، والتي تكرر الاستعانة بها في العديد من أبواب الكتاب، منها باب "تصغير الكلام"، وباب "تفضيل الديك على الطاووس"، وغيرها من الأبواب.

من الشخصيات الرئيسة التي تم الاستعانة بها في العديد من المرات شخصية "الهذلي"، وهو شاعر مخضرم، والهذليون مساكنهم في الحجاز، ولقد جاء له العديد من الأبيات الشعرية في الكتاب في العديد من الأحداث منها ما جاء في باب "قصة أذني النعامة":

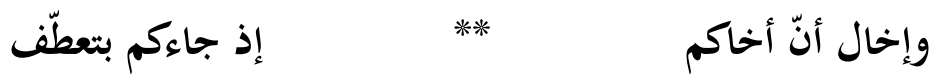

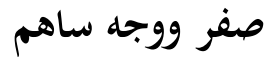

مثقال حبّة خردل
**

**

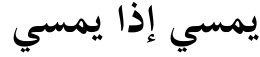

فغدا يمثّ ولا يرى

ومن الشخصيات الشعرية شخصية ابن أحمر الباهلي، والذي تم الاستعانة بالعديد

من أشعاره في مواقف مختلفة، منها ما جاء في باب "عيوب التيس والعنز"، قال:

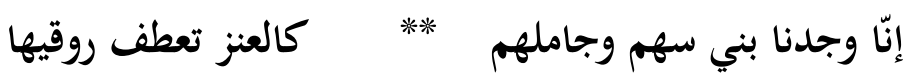

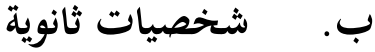

من الشخصيات الثانوية التي تناولها الكتاب شخصية لقمان بن عاد، وسنمار الرومي، وعبد

$$
\text { الرحمن بن الحكم، وغيرها العديد من الشخصيات الثانوية. }
$$

وهي الشخصيات التي يتكرر ذكرها داخل النص السردي، وهذه الشخصيات تقوم بوظيفة تنظيمية كروابط بين أجزاء القصة. يقول "فيليب هامون": إن "مرجعية النسق الخاص للعمل وحدها كافية لتحديد هويتها، فهذه الشخصيات تقوم داخل الملفوظ بنسج شبكة من 
El Sayed Mohamed Salem

الاستدعاء والتذكير، بأجزاء ملفوظية وذات أحجام متفاوتة كجزء من الجملة، كلمة، فقرة. ووظيفتها وظيفة تنظيمية وترابطية بالأساس. إنها بالأساس علامات تشحذ ذاكرة القارئ، إنها شخصيات للتبشير، وشخصيات لها ذاكرة، إنها تقوم بنذر أو تأويل الإمارات... الخ. إن الحلم التحذيري، ومشهد الاعتراف والتمني، والتكهن، والذكرى، والاسترجاع، والاستشهاد بالأسلاف، والصحو، والمشروع، وتحديد برنامج؛ كل هذه العناصر تعد أفضل الصفات، وأفضل الصحو لهذا النوع من الشخصيات (هامون، 1990 ص 25). أولا: الشخصيات التكرارية في كتاب "أخبار النساء" وكما ذكرنا من قبل أن من الشخصيات التكرارية في كتاب "أخبار النساء" شخصية "عمر بن الخطاب" --رضى الله عنه- كشخصية دينية تاريخية، فقد ورد كثير من الأخبار عن الشخصية، وعلى سبيل المثال لا الحصر ما جاء في باب "وصف النساء": "شكت امرأةٌ إلى زوجها قلّة إتيانه إليها، فقال لها: أنا وأنت على قضاء عمر. قالت: قضى عمر أنّ الرّجل إذا أتى امرأته في كلّ طهرٍ فقد أدّى حقّها (ابن الجوزي، 1982 ص 9).كما تكرر استخدام الشخصية في باب يذكر فيه "من صيره العشق إلى الأخلاط والجنون": "قال عمر بن الخطّاب رضي الله عنه: لو أدركت عفراء وعروة، لجمعت بينهما" (ابن الجوزي، 1982 ص 70). وقصة عروة بن حزام بن مهاصر من القصص الشهيرة في الحب، وهو أحد بني ضنة بن عبد بن كبير بن عذرة، وهو شاعر حجازي مشهور، كان يشبب بابنة عمه عفراء بنت

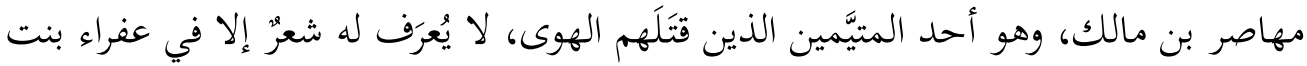
عمِّه عقال بن مهاصر (ابن منظور، د.ت ص 16 / 351).

وفي نفس الباب جاء أيضًا: "وقال عمر بن الخطّاب رضي الله عنه: اضربوهنّ بالعري (ابن الجوزي، 1982 ص 96). وتكررت الإحالة لأقوال سيدنا عمر في العديد من الأماكن؛ وذلك لما لشخصية سيدنا عمر من علامات قوية لذاكرة القارئ من أفعال وأقوال. 
El Sayed Mohamed Salem

ومن الشخصيات التكرارية في كتاب "أخبار النساء" شخصية معاوية بن أبي سفيان؛ عامل الشام لعمر بن الخطاب، ثم لعثمان بن عفان لعشرين سنة، والتي تكرر ذكرها في أكثر من موضع، منها في باب "ما جاء في وصف النساء": "ذكر أنّ معاوية بن أبي سفيان جلس ذات يوٍٍ بمجلسٍ كان له بدمشق على قارعة الطّريق (ابن الجوزي، 1982 ص 12). وأيضًا ما جاء في باب "ما جاء في الغيرة": "قال معاوية -رضي الله عنه-: ثلاث خصالٍ من السّؤدد: الصّلع، واندماج البطن، وترك الإفراط في الغيرة (ابن الجوزي، 1982 ص

وليست شخصية عمر بن الخطاب -رضى الله عنه-، ولا معاوية بن أبي سفيان من

الشخصيات التكرارية فقط، بل نجد العديد من الشخصيات سواء التاريخية أو الدينية... إلخ، نجدها من الشخصيات التكرارية في كتاب "أخبار النساء". منها على سبيل المثال لا الحصر شخصية "عبد الملك بن مروان"؛ نجده قد تكرر في فصول عدة، منها ما جاء في باب "أوصاف النساء": "قال عبد الملك بن مروان: من أراد أن يتّخذ جاريةً للمتعة فليتّخذها بربيّةً. ومن أراد للولد فليّتخذها فارسيّة، ومن أرادها للخدمة فليّخخذها روميّةً (ابن الجوزي، 1982 ص 11)، وأيضًا ما جاء في باب "من صيره العشق إلى الأخلاط والجنون" جاء فيه: "لما كتب إليها عبد الملك بن مروان بطلاقها، قال لها: إنّ أمير المؤمنين أمرني بطلاقك. قالت: هو والله أبرّ بي ممّن زوّجك إياي. فلمّا مات أبوها لم تبك عليه، فقيل لها في ذلك، فقالت: والله إنّ الحزن ليبعثني، وإنّ الغيظ ليصمتني (ابن الجوزي، 1982 ص 72). ثانيا: الشخصيات التكرارية في كتاب "البيان والتبيين" من الشخصيات التكرارية الدينية الهامة في كتاب "البيان والتبيين" شخصية سيدنا موسى بن عمران عليه السلام، والتي جاءت في العديد من فقرات الكتاب، منها للذكر لا للحصر ما 
El Sayed Mohamed Salem

جاء باب "عيوب البيان": "وقال موسى عليه السلام: (وَأَخِي هُرُونُ هُوَ أَفْصَحُ مِنّي لِِسَانا

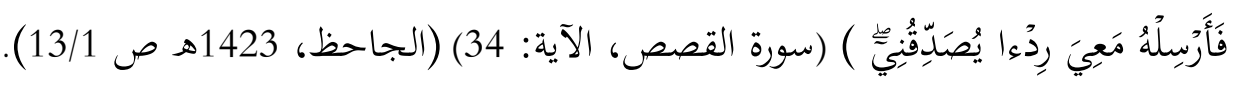
وأيضًا ورد في باب "من الخطب القصار": "لو كان أحد مكتفيًا من العلم لاكتفى

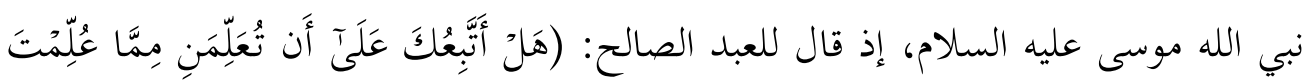
رُشُدا) (سورة الكهف، الآية: 66) (الجاحظ، 1423هـ ص 216). ولقد تكرر استخدام شخصية الجاحظ كشخصية تكرارية في الكتاب مرات عديدة، منها ما جاء في باب "عيوب البيان" بقوله: "قال أبو عثمان عمرو بن بحر، رحمه الله: اللهمّ إنّا نعوذ بك من فتنة القول كما نعوذ بك من فتنة العمل، ونعوذ بك من التكلّف لما لا نحسن كما نعوذ بك من العجب بما نحسن، ونعوذ بك من السّلاطة والهذر، كما نعوذ بك من العيّ والحصر . وقديمًا ما تعوذوا بالله من شرهما وتضرعوا إلى الله في السلامة منهما (الجاحظ، 1423هـ ص 27).وأيضًا ما جاء في ذكر حروف اللثغة بقوله: "ذكر الحروف التي تدخلها اللثغة وما يحضرني منها: قال أبو عثمان: وهي أربعة أحرف: القاف، والسين، واللام، والراء (الجاحظ، 1423هـ ص 51).

وأيضًا تكرر استخدام أقوال الشخصية في باب "الخطباء والشعراء": "قال أبو عثمان الجاحظ: ولم يرَ الناس أعجب حالا من الكميت والطرماح. وكان الكميت عدنانيَّا عصبيَّا، وكان الطرماح قحطانيَّا عصبيَّا. وكان الكميت شيعيًّا من الغالية، وكان الطرماح خارجيَّا من الصفرية. وكان الكميت يتعصب لأهل الكوفة، وكان الطرماح يتعصب لأهل الشام. وبينهما مع ذلك من الخاصة والمخالطة ما لم يكن بين نفسين قط، ثم لم يجرِ بينهما صرم ولا جفوة ولا إعراض، ولا شيء مما تدعو هذه الخصال إليه. ولم يرَ الناس مثلهما إلا ما ذكروا من حال عبد الله بن يزيد الإباضي، وهشام بن الحكم الرافضي، فإنهما صارا إلى المشاركة بعد الخلطة والمصاحبة (الجاحظ، 1423هـ ص 61). 
El Sayed Mohamed Salem

ولقد جاءت شخصية "على بن أبى طالب" من الشخصيات التكرارية المستخدمة في كتاب "البيان والتبيين"، والتي تقوم بوظيفة تنظيمية لربط أجزاء العمل، وذلك لتوضيح فكرة الكاتب وتقويتها باستخدام أحاديث لشخصية موثوق بها، وجاء في باب "خير الكلام الوسط": "وقال علي بن أبي طالب رحمه الله: 》اكن في الناس وسطاً وامشِ جانبًا《ٍ (الجاحظ، 1423هـ ص 214).

وجاء أيضًا في باب "الأسجاع في الكلام": "قال علي بن أبي طالب: 》أفضل العبادة الصمت، وانتظار الفرج) (الجاحظ، 1423هـ ص 245)، فهاهنا اقتباس ما بين حديثي رسول الله صلى الله عليه وسلم؛ الأول عن فضل الصمت: عن أنس بن مالك -رضي الله عنه-

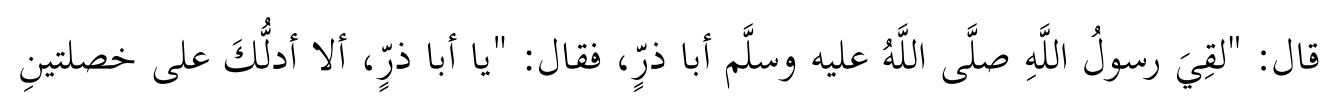
هما خفيفتانِ على الظُّهرِ وأثقالُ في الميزانِ من غيرِهما؟". قال: بلى يا رسولَ اللَّهِ. قال: "عليكَ

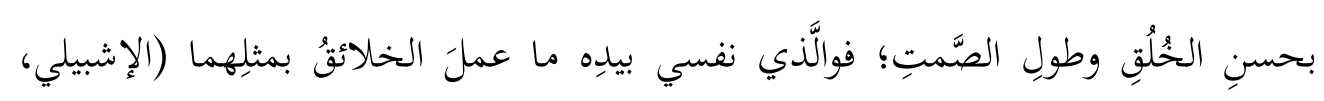
الأحكام الصغرى: 862 - صحيح)، و والحديث الثاني عن فضل انتظار الفرج: عن عبد الله بن مسعود -رضي الله عنه- قال: قال رسول الله صلى الله عليه وسلم: "سلوا اللهَ من فضلهِ؛ فإنَّ اللةَ يُحبُُ أن يُسألَ، وأفضلُ العبادةٍ انتظارُ الفرج. "(المنذري، الترغيب والترهيب: 2 |

$$
329 \text { - صحيح أو حسن أو ما قاربهما). }
$$

وأيضًا ما جاء في باب "طبقات الشعراء": "قال علي بن أبي طالب رضي الله عنه:

"رأي الشيخ أحب إلينا من جلد الشاب" (الجاحظ، 1423هـ ص 11/2). يعني لو دار الخيار بين أن يعطي أمرًا لشاب له جلد ونشاط، وبين أخذ رأي من رجل كبير السن؛ فإن رأي الشيخ أفضل لتمام الأمر. 
El Sayed Mohamed Salem

وفي باب "أدعية الصالحين" جاء قول علي رضي الله عنه: "اللهم إن ذنوبي لا تضرك، وإن رحمتك إياي لا تنقصك، فاغفر لي ما لا يضرك، وأعطني ما لا ينقصك (الجاحظ، 1823هـ ص 183/3

ثالثا: الشخصيات التكرارية في كتاب "الحيوان"

لم تختلف كثيرًا نوعية الشخصيات الموجودة في كتاب الحيوان عن باقي الكتب الأخرى، بل تشابهت الاختيارات بالاستعانة بنفس الشخصيات تقريبًا، فنجد شخصية سيدنا موسى بن عمران من الشخصيات المكررة في كتاب "الحيوان"، وعلى سبيل المثال لا الحصر في باب "ما ورد من الحديث والخبر في جزء تصغير الكلام": "ألا ترى أنّ موسى قال: اليت أنّ روح الله مع كلّ أحده (الجاحظ، 1423هـ ص 226). وأيضًا في باب "الورع" حيث قال: " فقال موسى: إنّ من الورع ما يبغصه الله (الجاحظ، 1423هـ ص 19/2). ومن الشخصيات التكرارية أيضًا شخصية علي بن أبي طالب -رضي الله عنه-، فقد ورد الكثير من كلماته ومواعظه وخطبه، وعلى سبيل المثال لا الحصر ما ورد في باب "تصغير الكلام": " وقال عليّ ابن أبي طالب رضي الله تعالى عنه: دققت الباب على رسول الله صلى الله عليه وسلم، فقال: من هذا؟ فقلت: أنا. فقال: أنا! كأنّه كره قولي: أنا (الجاحظ، 1423هـ

(224/1)

وأيضًا ما ورد في باب "أقذر الحيوان"، وهو يتحدث عن وصف اليعسوب بقوله: "قال علي بن أبي طالب -رضي الله عنه- في صلاح الزّمان وفساده: افإذا كان ذلك ضرب رك يعسوب الدّين بذنبها (الجاحظ، 1423هـ ص 157/3)، واليعسوب هي أم النحل، ولا يتم اختيارها إلا إذا كانت فيها تلك الصفات التي يعرفونها بالإلهام (أيوب، د. ت.ص 56). 
El Sayed Mohamed Salem

وتأتي شخصية سليمان -عليه السلام- في كثير من المواقف والأحداث في كتاب "الحيوان"، ولعل ذلك يأتي من منطلق ما أنعم الله على سليمان -عليه السلام-من نعم كثيرة؛ منها أنه سخَّر له الإنس والجن والطير، وجعلها تحت إمرته ، وعلّمه لغة الطير والحيوان على اختلاف أصنافها. وهو موضوع الكتاب نفسه ، وأنه يأتي على ألسنة الحيوانات. ومن هذه المواقف للمثال لا للحصر ما جاء في باب "فضل الكتاب": "قال الله عز وجل -وذكر

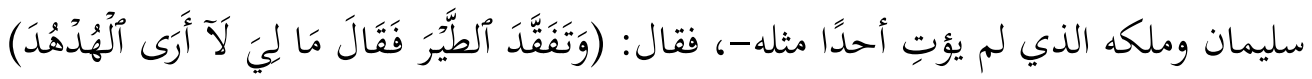
(سورة النمل، الآية: 20) (الجاحظ، 1423هـ ص 65/1). كما جاء في باب "أمثال في النمل " القصة الشهيرة لنبي الله سليمان -عليه السلاموالنملة: "فجعل تلك الجحرة مساكن. والعرب تسميها كذلك، ثمّ قال: (لَا يَحُطِمَنَّكُمْ سُلَيْمَنُ وَجُنُودُهُ، وَهُمْ لَا يَشُعُرُونَ) (سورة النمل، الآية: 18) (الجاحظ، 1423هـ ص 267)، وهي القصة الشهيرة والتي جمع فيها سيدنا سليمان عليه السلام جنوده من الإنس والجن والطير، ووزَّعهم كلا حسب منزلته، وأمرهم بالمسير في انتظام، بحيث لا يتقدّم أحد على أحد، وفيما هم يمشون، مرّوا على وادٍ من النمل، وكان النمل منشغلا في عمله، فلم ينتبه أحد لسليمان وجنوده إلا نملة كانت تراقب ما يقوم به النمل من عمل عن كَثَب، فشاهدتُ سليمانَ وجنودَه يتقدّمون نحوها، فخافتْ على نفسها وعلى أخواتها النمل أن يحطِّمها ويدوسها جيش سليمان دون قصد، فأسرعت خائفة نحو أخواتها من النمل، وقالت بصوت مرتجف ومتقطّع: أيها النمل أسرعوا وادخلوا في منازلكم؛ فإني رأيت سليمان وجنوده يتقدّمون نحونا.

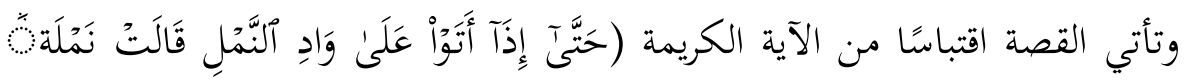

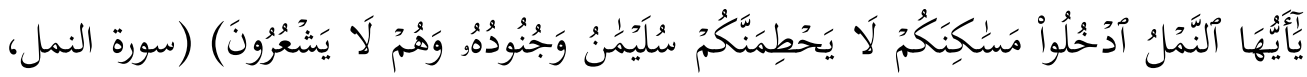
الآية: 18). 
El Sayed Mohamed Salem

ويأتي التكرار في باب "تأويل آية": "خرج سليمان بن داود - عليهما الصلاة والسلاميستسقي، فرأى نملة مستلقية على ظهرها، رافعة قوائمها إلى السماء وهي تقول: اللهمّ إنّا خلق من خلقك، ليس بنا غنى عن سقيك، فإمّا أن تسقينا وترزقنا، وإمّا أن تميتنا وتهلكنا! فقال:

$$
\text { ارجعوا فقد سقيتم بدعوة غيركم (الجاحظ، 1423هـ ص 269/4). }
$$

ولعل الحديث مقتبس عن حديث لأبي هريرة -رضي الله عنه-قال: "خرَج نبيٌّ منَ

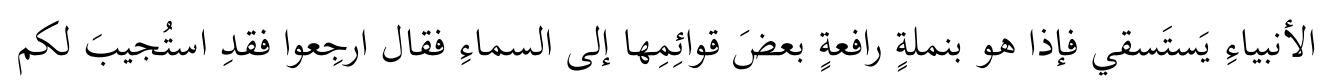

من أجلِ شأنِ النملةِ" (ابن الملقن، تحفة المحتاج: 1 / 564 - صحيح أو حسن). رابعا: الشخصيات التكرارية في كتاب "الإمتاع والمؤانسة"

من الشخصيات التكرارية في كتاب "الإمتاع والمؤانسة" شخصية معاوية بن أبي سفيان، والتي تكررت في العديد من الليالي، منها "الليلة العشرون" في قوله: “فيقول معاوية بن أبي سفيان: أخذها والله من عين صافية. (التوحيدي، 2003 ص 206).

كما تكررت الشخصية في "الليلة التاسعة والثلاثين": "وقال عبد الرّحمن بن خالد بن

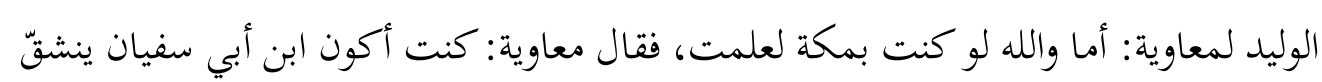
عني الأبطح، وكنت أنت ابن خالد منزلك أجياد، أعلاه مدرة، وأسفله عذرة. (التوحيدي، (381) 2003

وجاءت شخصية علي بن أبي طالب من الشخصيات التكرارية أيضًا في "الإمتاع والمؤانسة"، ومنها ما جاء في "الليلة التاسعة عشرة": "وقال عليّ بن أبي طالب - كرّم الله وجهه- لرجل من بني تغلب يوم صفّين: آثرتم معاوية؟ فقال: ما آثرناه، ولكنّا آثرنا القسب الأصفر، والبرّ الأحمر، والزّيت الأخضر. (التوحيدي، 2003 ص 199). وجاء في "الليلة العشرين": "قال أمير المؤمنين عليّ بن أبي طالب - عليه السلامفي جوابه لي: لو فعلنا ذلك فجعلها في غيرنا بعد كلامنا لم ندخل فيها أبدًا، فأحببت أن 
El Sayed Mohamed Salem

أكفّ، فإن جعلها فينا فهو الذي نريد، وإن جعلها في غيرنا كان رجاء من طلب ذلك منا ممدودًا. (التوحيدي، 2003 ص 207). كما جاءت شخصية "سليمان المنطقي"، فجاء في "الليلة الثانية": "أوّل ما أسألك عنه حديث أبي سليمان المنطقيّ كيف كان كلامه فينا" (التوحيدي، 2003 ص 48). كما جاء أيضًا في "الليلة السادسة": "وأبو سليمان يقول من الجماعة: العرب أذهب مع صفو العقل، ولذلك هم بذكر المحاسن أبده، وعن أضدادها أنزه. ولو كانت روّيتهم في وزن بديهتهم، كان الكمال (التوحيدي، 2003 ص 79) ، وأيضًا في "الليلة التاسعة": "وقال أبو سليمان لنا في هذه الأيام: الإنسان بين طبيعته وهي عليه، وبين نفسه وهي له؛ كالمنتهب المتوزّع، فإن استمد من العقل نوره وشعاعه قوي ما هو له من النفس، وضعف ما هو عليه من الطبيعة، وإلا فقد قوي ما هو عليه من الطبيعة وضعف ما هو له من النفس. (التوحيدي، 2003 ص 110). ومن الشخصيات التكرارية في الكتاب شخصية ابن المقفع، جاء في (الليلة الرابعة): "كان ابن المقفع يقف قلمه كثيرًا، فقيل له في ذلك، فقال: إن الكلام يزدحم في صدري فيقف

$$
\text { قلمي لأتخيره. (التوحيدي، } 2003 \text { ص 66). }
$$

وجاء في (الليلة السادسة): "إذ أقبل علينا ابن المقفع، فقال: أيّ الأمم أعقل؟ فظننا أنه يريد الفرس، فقلنا: فارس أعقل الأمم، نقصد مقاربته، ونتونَّى مصانعته. فقال: كلا، ليس ذلك لها

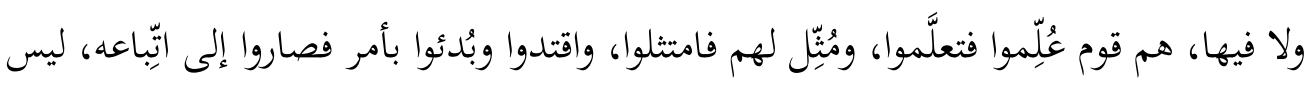
لهم استنباط ولا استخراج. فقلنا له: الروم. فقال: ليس ذلك عندها، بل لهم أبدان وثيقة وهم أصحاب بناء وهندسة، لا يعرفون سواهما، ولا يحسنون غيرهما(التوحيدي، 2003 ص 70)، وتكرر ذكره أيضا في "الليلة السابعة عشر".

الخلاصة 
El Sayed Mohamed Salem

السرد هو الطريقة التي تُحكى بها أحداث الرواية، وهو ليس حكرًا على فن واحد من فنون الأدب؛ فهو قائم في الأسطورة والحكاية، والكوميديا والتراجيديا، وفي الرواية والقصة القصيرة والسيرة أيضًا. ويتميز السرد بأنه قصير وهادف، وينبع من الواقع التاريخي، والإنسان فطر على حب الأخبار القصصية والولع بها، والتشوق لسماعها رغبة في التأثر والإمتاع، وهذا ما يبرر ذلك الاتساع الكبير لها بين آداب الشعوب المختلفة، فالأسلوب القصصي محبب إلى النفوس.

وقد امتلأت كتب الأدب في العصر العباسي بكثير من الحكايا والقصص والأخبار والأحداث السياسية والاجتماعية والدينية، التي عبّرت عن الحياة والمجتمع في العصر العباسي . وقد تنوعت وتعددت الشخصيات في كتب الأدب العباسي بين شخصيات مرجعية، وشخصيات رئيسة وثانوية، وشخصيات تكرارية، مما حقق التشويق والمتعة، وجعل النصوص السردية أكثر فنية وجمالا، وهو ما ظهر جليا في الكتب الأولى للسرد الحكائي المكتوب، والتي تم الوقوف على نماذج منها والتعليق عليها بشكل موجز . وقد توصل البحث في نهايته إلى نتائج؛ أهمها:

الشخصية السردية هي أهم مكونات العمل الحكائي؛ فهي العنصر الحيوي الذي ينهض بالأفعال التي تترابط وتتكامل في الحكي، وهي المحرك للأحداث والدافع بها إلى التطور، بل هي عمود البناء الروائي القصصي، ولا يمكن قيام العمل الحكائي بدونها، ولقد تنوعت الشخصيات السردية بحسب في الأعمال الأدبية في العصر العباسي؛ فقد جاءت الشخصية المرجعية، وكذا الشخصية التكرارية، علاوة على الشخصية الثانوية المرحلية، وكل منها أدى دوره السردي ووظيفته الحكائية بشكل لافت وأداء عالٍ.

إن للشخصية السردية دورا فاعلا، وحضورا طاغيا في تجلية القضية السردية، والفكرة

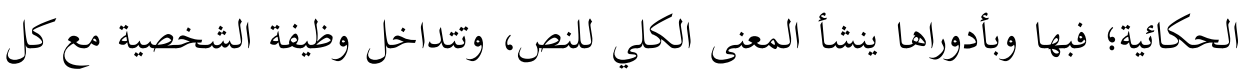


El Sayed Mohamed Salem

عناصر السرد الأخرى؛ إذ إنها العنصر الوحيد الذي يملك التفاعل الفضاء الزمكاني والزماني، وتظهر من خلالها فنيات السرد وتقنياته.

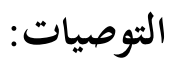

وفي نهاية البحث يجد البحث ما يوصي به المهتمين والباحثين من أن يتم تناول الشخصيات السردية في العصر العباسي من وجهة سيكلوجية نفسية؛ للوقوف على أسرار استدعاء مثل هذه الشخصيات وأثرها في العمل الأدبي ومردودها الفني على نفسية المتلقي.

إعادة النظر في التراث الحكائي العباسي؛ حيث إنه ضم جميع أنواع الحكي وأشكاله وهذا بدوره يحوي جماليات أدبية، وتجليات إبداعية أثرت البناء السردي وأثنته في تأسيس نظرية للحكي في العصر العباسي لها أسلوبها وطابعها الخاص، والتي بحاجة إلى إظهار ملامحها وتبيين معالمها

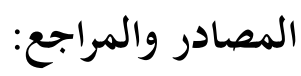

$$
\text { ثانيا: المراجع العربية آلقران الكريم. }
$$

أحمد، مرشد، البنية والدلالة في روايات إبراهيم نصر الله، ط1، (بيروت: دار فارس للنشر، $\cdot()^{2005}$ أرسطو، طاليس، فن الشعر، ترجمة: عبد الرحمن بدوي، د.ط، (بيروت: دار الثقافة، .) 1973

$$
\begin{aligned}
& \text { بحراوي، حسن، بنية الشكل الروائي (الفضاء - الزمن - الشخصية)، ط2، (الدار البيضاء - } \\
& \text { المغرب: المركز الثقافي العربي، 2009م). }
\end{aligned}
$$


El Sayed Mohamed Salem

بحراوي، حسن، بنية الشكل الروائي، ط1، (بيروت: المركز الثقافي العربى، 1990م). بنكراد، سعيد، شخصيات النص السردي، البناء الثقافي، د.ط، (المغرب: منشورات جامعة المولى إسماعيل مكناس، 1994م).

بويجرة، محمد بشير، بنية الشخصية في الرواية الجزائرية، د.ط، (الجزائر: ديوان المطبوعات

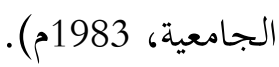

التوحيدي، أبو حيان، الامتاع والمؤانسة، تحقيق: محمد الفاضلي (بيروت: دار الجيل للطبع والنشر والتوزيع، 2003م).

الجاحظ، أبو عثمان عمرو بن بحر بن محبوب بن فزارة الليثي الكناني البصري، البيان والتبيين،

$$
\text { د.ط، (بيروت: دار ومكتبة الهلال، 1423هـ). }
$$

الجاحظ، أبو عثمان عمرو بن بحر بن محبوب بن فزارة الليثي الكناني البصري، الحيوان،

$$
\text { ط2، (بيروت: دار الكتب العلمية، 1424هـ). }
$$

ابن الجوزي، جمال الدين أبو الفرج عبد الرحمن بن علي بن محمد، أخبار النساء، شرح وتحقيق: نزار رضا، د.ط، (بيروت - لبنان: دار مكتبة الحياة، 1982م).

الحجلان، ناصر، الشخصية في قصص الأمثال العربية، ط1، (الرياض: النادي الأدبي، $\cdot(2009$

أبو حيان، علي بن محمد بن العباس التوحيدي، الإمتاع والمؤانسة، راجعه: هيثم خليفة الطعيمي، ط1، (بيروت: المكتبة العصرية، 1424هـ).

الذهبي، محمد بن أحمد بن عثمان، سير أعلام النبلاء، د.ط، (بيروت: مؤسسة الرسالة،

$$
\text { . } 1422 \text { هـ / } 2001
$$

الزمخشري، أبو القاسم محمود بن عمر بن محمد بن عمر الخوارزمي، أساس البلاغة، تحقيق: محمد باسل، ط1، (بيروت: دار الكتب العلمية، د. ت.). 
El Sayed Mohamed Salem

طالب، أحمد، جماليات المكان في القصة القصيرة الجزائرية، د.ط، (الجزائر: دار الغرب

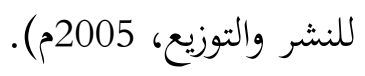

قاسم، سيزا أحمد، بناء الرواية دراسة مقارنة في ثلاثية نجيب محفوظ، د.ط، (القاهرة:

$$
\text { الهيئة المصرية العامة للكتاب، ع } 91 \text { (م). }
$$

مرتاض، عبد الملك، في نظرية الرواية - بحث في تقنيات الكتابة الروائية، د.ط، (الجزائر:

$$
\text { دار الغرب للنشر والتوزيع، د. ت. ت. }
$$

ابن منظور، أبو الفضل محمد بن مكرم بن علي، لسان العرب، د.ط، (د.م: الدار المصرية

$$
\text { للتأليف والترجمة - طبعة مصورة عن طبعة بولاق، د.ت). }
$$

ناصر، أحمد عبد الرزاق، تقنيات السرد في عالم نجم والي الروائي، رسالة ماجستير،

$$
\text { (العراق: جامعة بغداد، 2010م). }
$$

هامون، فليب، سيميولوجية الشخصيات الروائية، ترجمة: سعيد بنكراد، د.ط، (الرباط: دار

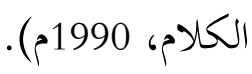

$$
\text { يقطين، سعيد، قال الراوي، ط1، (بيروت: المركز الثقافي العربي، 1997م). }
$$

